DOI:10.5216/cab.v12i2.626

\title{
PARÂMETROS HEMATOLÓGICOS, FUNÇÃO RENAL E HEPÁTICA DE CÃES DA RAÇA DOGUE ALEMÃO EM CRESCIMENTO SUPERALIMENTADOS
}

\author{
Severiana Cândida Medonça Cunha Carneiro¹, Luiz Henrique da Silva², Maria Clorinda Soares \\ FIORAVANTTI ${ }^{3}$, José HENRIQUe STRINGHIN ${ }^{3}$
}

1 - Médica Veterinária, Doutora em Ciência Animal - HV/EVZ/UFG - severianacunha@uol.com.br

2 - Mestrando em Ciência Animal - EVZ/UFG

3 - Professores Doutores - EVZ/UFG

\section{RESUMO}

Uma dieta apropriada é importante e os erros nutricionais podem ter consequências irreparáveis. Atualmente, a obesidade é a doença nutricional mais comum em cães, com prevalência de $16 \%$. Em cães, o nível de atividade física, composição dietética, sabor do alimento e estilo de vida são os fatores mais importantes que contribuem para a obesidade. Este trabalho foi desenvolvido no sentido de avaliar os efeitos da superalimentação na bioquímica clínica e hematologia de filhotes saudáveis. Foram estudados 14 cães da raça Dogue Alemão, machos, 10 semanas de idade, durante 27 semanas. O delineamento experimental foi inteiramente casualizado, com dois tratamentos, sete repetições e seis meses de duração. Os tratamentos constituíram-se de dieta super prêmio ofertada à vontade (GI) (tratamento 1) e com quantidade restrita (GII) (tratamento 2). Procedeu-se a avaliação da bioquímica sanguínea e urinária e a determinação dos parâmetros hematológicos. Constatou-se que filhotes superalimentados apresentaram elevações séricas de alfa1 globulina e menores valores de beta globulina, gama globulina, ALT, ALP e creatinina. No hemograma observaram-se maiores valores de linfócitos e menores valores no eritrograma. $\mathrm{O}$ índice proteína urinária: creatinina urinária não apresentou diferença entre os tratamentos.

PALAVRAS-CHAVE: Alimentação à vontade; canino; hematologia; parâmetros bioquímicos.

\section{HEMATOLOGY, RENAL AND HEPATIC FUNCTION IN OVERFED GREAT DANE PUPPIES}

An adequate diet is important and nutritional errors may lead to irrevocable consequences. Nowadays, obesity is the most common nutritional disease in dogs, with a prevalence of $16 \%$. In dogs, the level of physical activity, diet composition, food taste, and lifestyle are the most important factors which contribute to obesity. This study was carried out in order to assess the effects of overfeeding on clinical biochemistry and hematology of healthy puppies. Fourteen male Great Dane dogs at 10 weeks of age were studied during 27 weeks. The 
experimental design was completely randomized, with two treatments, seven replications, and six months of duration. Treatments were made up of super premium diet given ad libitum (GI) (treatment 1) and restrictedly (GII) (treatment 2). The evaluation of blood and urinary biochemistry as well as the determination of hematological parameters were carried out. It was concluded that overfed puppies revealed seric elevations of alpha1 globulin, and lower values of beta globulin, gamma globulin, ALT, ALP, and creatinine. In blood evaluation, higher values of lymphocytes and lower values in the erythrogram were observed. The urinary protein:urinary creatinine value did not reveal any difference between treatments.

KEYWORDS: Ad libitum feed; biochemical parameters; canine animal; hematological parameters.

\section{INTRODUÇÃO}

A proximidade dos animais de estimação com os seres humanos, o acesso a dietas com alta densidade energética, petiscos e guloseimas e a redução de atividades físicas vêm predispondo-os à obesidade (EDNEY \& SMITH, 1986; ARMSTRONG \& LUND, 1996; JERICÓ \& SCHEFFER, 2002). A obesidade é a doença nutricional mais comum em seres humanos, cães e gatos que vivem nas sociedades desenvolvidas. Dados nacionais expressam prevalência de $16 \%$ de obesidade em cães (JERICÓ \& SCHEFFER, 2002), números inferiores aos descritos em outros países, nos quais se reporta entre $24 \%$ e 30\% de cães com sobrepeso (EDNEY \& SMITH, 1986; LEWIS et al., 1994).

O excesso de peso pode acarretar diversos efeitos deletérios sobre a saúde dos animais. Dentre eles, os mais importantes são os distúrbios do aparelho locomotor, hipertensão arterial, prejuízos à resposta imunológica, aumento da incidência de diabetes mellitus tipo II, dermatopatias, neoplasias, intolerância ao calor, menor eficiência reprodutiva e decréscimo na função hepática (HAND et al., 1989, LEWIS et al., 1994, JERICÓ et al., 2006).

A avaliação da bioquímica sanguínea na monitorização clínica da obesidade é de fundamental importância. A determinação das concentrações séricas de proteínas vem se tornando um procedimento valioso para o entendimento dos processos fisiopatológicos, sendo utilizadas em animais sadios e doentes (ECKERSALL, 2000). A análise hematológica proporciona uma ampla variedade de informações que completam os achados bioquímicos, inclusive quando a maioria dos achados hematológicos são normais e usados para excluir diferentes diagnósticos diferenciais (BUSH, 1999).

Estudos das mudanças fisiológicas decorrentes dos efeitos nutricionais em diferentes idades são cada vez mais necessários com o aumento na expectativa de vida dos animais de companhia, em parte atribuída à melhora da qualidade das dietas e acesso ao atendimento veterinário. Ao identificar mudanças hematológicas e o perfil bioquímico sérico relacionado ao fígado e aos rins no decorrer da vida dos animais, pesquisadores podem desenvolver formulações e métodos alimentares mais apropriadas para cada estágio de vida.

Pelo presente trabalho, objetivou-se verificar, por meio do acompanhamento laboratorial - bioquímica clínica e hemograma - a higidez de filhotes da raça Dogue Alemão superalimentados.

\section{MATERIAL E MÉTODOS}

O experimento foi realizado no Hospital Veterinário da Escola de Veterinária e Zootecnia da Universidade Federal de Goiás. Empregaram-se 14 filhotes da espécie canina, da raça Dogue Alemão, do sexo masculino, com peso corpóreo médio inicial de $8 \mathrm{Kg}$ e dez semanas de idade, provenientes de seis ninhadas diferentes, adquiridas em canis particulares dos estados de Goiás, Minas Gerais, São Paulo e Distrito Federal. A seleção dos cães deu-se após investigação sistematizada, na qual foram avaliadas as condições clínicas e ortopédicas por manobras semiológicas rotineiras.

Antes do início do experimento os filhotes passaram por um período de adaptação de sete dias, em que receberam a mesma ração comercial seca extrusada (Ossobuco large size filhotes, super prêmio - Nutron Alimentos, Campinas, SP) utilizada na fase experimental. Nessa etapa, os animais também receberam ecto e endoparasiticidas e foram primoimunizados com vacina polivalente (Galaxy DA2PPvl + CV, Fort Dodge Animal Health-EUA) contra parvovirose, leptospirose, cinomose, coronavirose, adenovirose, parainfluenza e hepatite viral, recebendo posteriormente três doses de reforço, com intervalos de 21 dias.

O delineamento experimental foi inteiramente casualizado, com dois tratamentos e sete repeti- 
ções. Os 14 filhotes foram distribuídos em cada grupo de modo que cada ninhada fosse igualmente representada em ambos os tratamentos. Foram constituídos dois grupos de sete animais cada, sendo o primeiro grupo (GI) com cães tratados com ração à vontade e o segundo grupo (GII) com cães tratados com ração com restrição. Os cães foram tatuados com números na orelha direita.

$\mathrm{O}$ experimento compreendeu um período de 27 semanas, sendo que todos os animais receberam água à vontade e permaneceram no mesmo alojamento com os mesmos horários fixos de alimentação. A composição da ração seca extrusada fornecida para os cães do experimento está descrita na Tabela 1.

TABELA 1 - Composição nutricional da ração comercial seca extrusada (Ossobuco large size filhotes) utilizada no experimento

\begin{tabular}{lc}
\hline Componente & Valores em matéria seca \\
\hline Matéria Seca (\%) & 100 \\
Umidade (\%) & 12 \\
Proteina Bruta (\%) & 34 \\
Extrato Etéreo (\%) & 16 \\
Cálcio (\%) & 1,5 \\
Fósforo (\%) & 1 \\
Matéria Fibrosa (\%) & 3 \\
Matéria Mineral (\%) & 9 \\
Energia Metabolizável (k & 3400 \\
Aflatoxina (ppb) & 20 \\
Salmonella & Ausência em 25g \\
\hline
\end{tabular}

Fonte: Nutron Alimentos, Campinas, SP

O fornecimento da ração variou de acordo com os tratamentos adotados neste experimento. Para os cães do GI, o fornecimento foi livre e individual das $8 \mathrm{~h}$ às $18 \mathrm{~h}$. A quantidade de ração fornecida e as sobras ao final do dia eram pesadas, de modo a permitir o cálculo do consumo diário individual de cada animal. Para o GII, a ração foi fornecida em quantidades preestabelecidas pelo fabricante, calculada levando-se em consideração a idade e o peso corporal. Como os cães foram pesados a cada sete dias, o ajuste da quantidade de ração foi feito semanalmente. Foram fornecidas três refeições individuais diárias, às $7 \mathrm{~h}, 12 \mathrm{~h}$ e $30 \mathrm{~min}$ e às $17 \mathrm{~h}$. Foi estabelecido o tempo máximo de 30 min para cada refeição. No momento do fornecimento da ração, cada filhote foi colocado sozinho em uma baia, onde permanecia até atingir o tempo estabelecido para in- gestão ou consumir todo o alimento disponibilizado.

Os cães do GI foram alojados em baias individuais, de $1,96 \mathrm{~m}$ por $2,92 \mathrm{~m}$, com piso de cimento rústico, paredes de alvenaria com iluminação e ventilação natural por aberturas laterais nas paredes. Os do GII, fora do período de alimentação, foram alojados em duas baias coletivas de $3,92 \mathrm{~m}$ x 5,84m, piso de cimento rústico, paredes de alvenaria com iluminação e ventilação natural por meios de aberturas laterais nas paredes.

Todos os dias, os cães dos dois grupos foram levados para o solário para realização de exercícios físicos, por duas vezes, das $7 \mathrm{~h}$ às $8 \mathrm{~h}$ e das $16 \mathrm{~h}$ às $17 \mathrm{~h}$ horas. Nos dias em que eram realizadas as medições, os filhotes eram colocados no solário às $8 \mathrm{~h}$ $30 \mathrm{~min}$, onde permaneceram até as $11 \mathrm{~h} 30 \mathrm{~min}$.

Os filhotes dos dois grupos foram observados três vezes ao dia, no horário em que os cães do grupo restrito recebiam a alimentação e nos dias das medições. Um exame clínico detalhado (determinação da temperatura corporal, frequência cardíaca, frequência respiratória e pulso, avaliação da pele e mucosas, palpação dos linfonodos e das articulações) era realizado sempre que um animal apresentava alguma alteração comportamental ou em seu estado geral.

Foram realizadas 27 colheitas de sangue e de urina, em intervalos regulares de sete dias com os animais em jejum alimentar mínimo de 12 horas, para realização dos seguintes exames: perfil bioquímico sanguíneo (proteína total, uréia, creatinina, alanina aminotransferase e fosfatase alcalina) e bioquímica urinária (proteína e creatinina). Para realização do hemograma e perfil eletroforético de proteínas séricas foram realizadas 14 colheitas de sangue com intervalos quinzenais. As amostras de sangue foram obtidas por punção da veia jugular com os animais mantidos em decúbito lateral e as amostras de urina foram colhidas por cateterização da uretra, com os animais mantidos em estação.

Todas as avaliações laboratoriais foram realizadas no Laboratório de Patologia Clínica do HV/EVZ/UFG. Para cada metabólito analisado foram utilizados reagentes comerciais padronizados (Labtest ${ }^{\circledR}$, Labtest Diagnóstica S.A., Lagoa Santa, $\mathrm{MG})$. As reações ocorreram à temperatura de $37^{\circ} \mathrm{C} \mathrm{e}$ a leitura realizada em espectrofotômetro manual (Micronal B 342, São Paulo, SP).

Para os testes bioquímicos na urina, as amostras de $20 \mathrm{~mL}$, após a colheita, foram centrifugadas, divididas em microtubos de polipropileno de $1,5 \mathrm{~mL}$ (Eppendorf®, Alemanha) e refrigeradas até o mo- 
mento da realização dos exames.

Para realização do hemograma foram colhidos $5 \mathrm{~mL}$ de sangue utilizando-se tubos à vácuo (Vacutainer ${ }^{\circledR}$, Becton Dickinson Ind. Cirúrgicas Ltda, Brasil) de vidro e com anticoagulante EDTA (ácido etilediaminotetracético, sal dissódico). O exame foi realizado no período máximo de seis horas, utilizando-se analisador hematológico automático (Analisador Hematológico ABX Modelo Micros 60, França). A contagem diferencial de leucócitos foi feita em esfregaços sanguíneos.

Para realização da bioquímica sérica, foram colhidos $10 \mathrm{ml}$ de sangue em tubo vacutainer ${ }^{\circledR}$ descartáveis e sem anticoagulante. Após retração do coágulo e obtenção do soro, os tubos foram centrifugados. Em seguida, o soro foi separado por aspiração, dividido em alíquotas, mantido sob refrigeração, por no máximo seis horas, e as provas bioquímicas realizadas em, no máximo, 12 horas.

A proteína sérica total foi determinada pelo método colorimétrico, por reação com biureto e leitura em comprimento de onda de $550 \mathrm{~nm}$. As frações proteicas foram separadas pela técnica de eletroforese em gel de agarose, utilizando-se tampão tris $\mathrm{pH} 9,5$ gelado $\left(2^{\circ}\right.$ a $\left.8^{\circ} \mathrm{C}\right)$, sendo corados em negro de amido (amido black 10-B - art.1810 CELM) a $0,1 \%$ em ácido acético a $5 \%$. A leitura do filme foi realizada por densitometria, em $520 \mathrm{~nm}$, utilizando-se o sistema SE-250 da CELM, de acordo com metodologia descrita pelo fabricante.

A uréia foi determinada pelo método enzimático-colorimétrico, por reação com uréase, e a leitura feita em comprimento de onda de $600 \mathrm{~nm}$. A creatinina sérica foi determinada por método colorimétrico, por reação com picrato alcalino, sendo realizada a leitura em comprimento de onda de $520 \mathrm{~nm}$.

A alanina aminotransferase (ALT) e a fosfatase alcalina (ALP) foram determinadas pelo método Frankel Reitman e Roy modificado, respectivamenTABELA 2 - Hemograma dos cães alimentados com dieta super prêmio dos GI e GII, com valores de média, desvio-padrão e coeficiente de variação.

\begin{tabular}{|c|c|c|c|}
\hline Variáveis & $\begin{array}{c}\text { GI } \\
\text { Média } \pm \text { Desvio-padrão }\end{array}$ & $\begin{array}{c}\text { GII } \\
\text { Média } \pm \text { Desvio-padrão }\end{array}$ & Valores de referência ${ }^{*}$ \\
\hline Hemácias $\left(\mathrm{x} 10^{6} \mu \mathrm{L}\right)$ & $5,37^{\mathrm{B}} \pm 0,68$ & $5,68^{A} \pm 0,66$ & $5,5-8,5$ \\
\hline Hemoglobina ( $\mathrm{g} / \mathrm{dL})$ & $11,70^{\beta} \pm 1,35$ & $12,22^{A} \pm 1,30$ & $12-18$ \\
\hline Hematócrito\% & $35,93^{\mathrm{B}} \pm 3,84$ & $37,23^{4} \pm 4,22$ & $37 \%-55 \%$ \\
\hline Leucócitos $\left(\times 10^{3} \mu \mathrm{L}\right)$ & $14.761,24^{A} \pm 5.541,33$ & $14.498,02^{A} \pm 6.446,83$ & $6000-17000$ \\
\hline Neutrófilos $\left(x 10^{3} \mu \mathrm{L}\right)$ & $8329,27^{A} \pm 3728,91$ & $8806,16^{A} \pm 4963,44$ & $3000-11500$ \\
\hline Linfócitos $\left(x 10^{3} \mu \mathrm{L}\right)$ & $4200,45^{A} \pm 2072,48$ & $3522,01^{B} \pm 2073,20$ & $1000-4800$ \\
\hline
\end{tabular}

AB Médias seguidas de letras diferentes, dentro da mesma linha, diferem estatisticamente pelo teste de Wilcoxon $(\mathrm{p}<0,05)$. *BUSH (1999) te. A leitura foi feita em espectrofotômetro com comprimento de onda de $505 \mathrm{~nm}$ para a ALT e 590 $\mathrm{nm}$ para ALP (Labetest).

A determinação da concentração de proteína urinária foi feita utilizando-se método colorimétrico, por reação coomassie azul brilhante em absorbância de $610 \mathrm{~nm}$. A creatinina urinária foi determinada pelo método colorimétrico, por reação com picrato alcalino, sendo realizada a leitura em comprimento de onda de $520 \mathrm{~nm}$.

O índice proteína urinária:creatinina urinária foi calculado conforme citado por FINCO (1995), dividindo-se os valores de proteína urinária pelos de creatinina urinária, visando à verificação de lesão tubular renal.

Procedeu-se a análise estatística descritiva para verificação dos valores de média e desvio-padrão. Para cada variável analisada no estudo fez-se a comparação dos dois tratamentos, considerando-se os dados gerais e os de cada período de avaliação. Considerando que as variáveis sanguíneas e urinárias e os cálculos delas originados (relação proteína urinária/creatinina urinária) não apresentaram normalidade e homogeneidade de variância simultaneamente, utilizaram-se a análise não paramétrica e o teste de Wilcoxon, 5\% de significância (SAMPAIO,1998). Os testes estatísticos foram realizados pelo programa computacional SAEG (UFV, 2003).

\section{RESULTADOS E DISCUSSÃO}

Os valores de média e desvio padrão das hemácias, hemoglobina, hematócrito, leucócitos totais, neutrófilos e linfócitos determinados no sangue dos cães deste trabalho e os valores de referência utilizados estão descritos na Tabela 2. 
O valor médio de hemácia do GI foi superior $(p<0,05)$ em relação ao GII. Entretanto, os valores dos dois grupos ficaram dentro dos limites de normalidade (BUSH, 1999). Analisando cada colheita individualmente, detectou-se que, durante o período experimental, não houve diferença significativa entre os grupos.

Os valores médios de hemoglobina apresentaram diferença estatística, sendo superior $(\mathrm{p}<0,05)$ no GI $(12,22 \mathrm{~g} / \mathrm{dL})$ em relação ao GII $(11,70 \mathrm{~g} / \mathrm{dL})$. Esses valores estão dentro dos intervalos de referência (BUSH, 1999). Ao longo do período experimental, apenas na quinta semana houve diferença, sendo superior no GII $(11,24 \mathrm{~g} / \mathrm{dL})$ vs. GI $(10,67 \mathrm{~g} / \mathrm{dL})$.

O hematócrito apresentou valores médios de $35,93 \%$ e $37,23 \%$ para os cães do GI e do GII, respectivamente, havendo, portanto, diferença entre eles, sendo superior no GII. No entanto, esses valores ficaram dentro dos intervalos de referência (BUSH, 1999). Durante as semanas do experimento não houve diferença estatística.

De acordo com NELSON \& COUTO (2001), quando se avalia a série eritróide, o clínico não precisa analisar todos os valores no hemograma completo, porque fornecem informação idêntica. Neste estudo, o valor do hematócrito refletiu comportamento semelhante ao das hemácias e das hemoglobinas, corroborando com esses autores (Figura 1).

NAP et al. (1991) estudaram os efeitos de três dietas com diferentes níveis de proteína $(14,6 \%$, $23,1 \%$ e $31,6 \%$ ) e não observaram diferenças entre os valores de hemácias e hematócrito. Entretanto, FERREIRA (2006) encontrou diferenças entre os grupos, que receberam dieta com variação dos teores de proteína $(12 \%, 22 \%$ e $32 \%)$, sendo o hematócrito superior no grupo alimentado com maior teor de proteína. Os resultados deste presente estudo diferiram desses dois trabalhos, pois os maiores valores foram detectados nos cães que receberam alimentação restrita, ou seja, os que receberam menos proteína.

Segundo LIPPERT (1992) e AGAR (2001), as hemácias são células que apresentam metabolismo elevado, portanto, necessitam de energia prontamente utilizável para manutenção da sua atividade normal, e a redução de reservas protéicas e energéticas no organismo pode resultar em anemia. Ao contrário do esperado, neste estudo os cães que tiveram restrição alimentar apresentaram maiores valores de eritrócitos, hemoglobina e hematócrito.

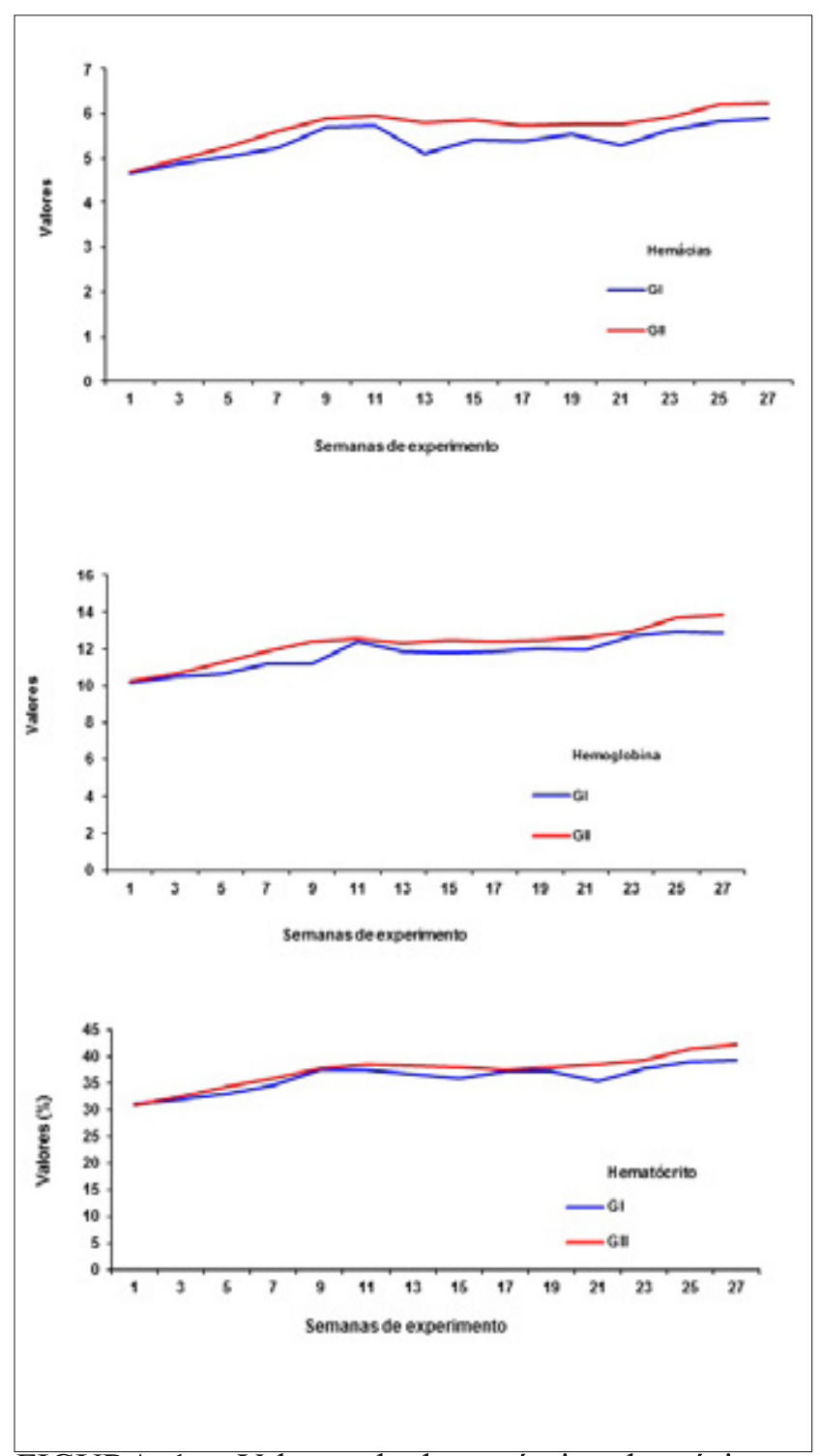

FIGURA 1 - Valores do hematócrito, hemácias e hemoglobina dos cães dos grupos GI e GII, ao longo do período de avaliação.

Os valores absolutos médios de neutrófilos ficaram dentro dos intervalos de referência e não houve diferença significativa $(p>0,05)$. Durante $o$ período experimental, houve diferença $(\mathrm{p}<0,05)$ apenas na terceira semana do experimento. Os filhotes do GII foram mais estressados quando comparados com os cães do GI, provavelmente devido à restrição alimentar ter sido severa durante o período experimental, o que pode ter contribuído para os valores mais altos de neutrófilos nesse grupo.

Os valores médios de linfócitos absolutos apresentaram diferença significativa $(p<0,05)$, sendo superior no GI em relação ao GII. Esses valores estão dentro dos intervalos de referência e, ao longo do período experimental, não houve diferença estatística. 
Os valores de média e desvio padrão dos metabólitos determinados no soro dos cães deste trabalho e os valores de referência utilizados estão descritos na Tabela 3.

Os valores médios de albumina foram de $2,30 \mathrm{~g} / \mathrm{dL}$ e $2,23 \mathrm{~g} / \mathrm{dL}$, respectivamente, para os grupos GI e GII, não havendo diferença estatística entre eles. De acordo com NAOUM (1999), a análise quantitativa dessa proteína tem importante significado clínico, pois a sua diminuição pode estar relacionada a um defeito de sua síntese hepática ou a perdas renais. Esses valores ficaram dentro dos intervalos de referência (HARRUS et al. (1996). Nos períodos analisados, foram identificadas variações entre os grupos GI e GII apenas na $11^{\mathrm{a}}$ semana $(2,21 \mathrm{~g} / \mathrm{dL}$ vs. $2,04 \mathrm{~g} / \mathrm{dL})$, conforme Figura 2.

TABELA 3 - Bioquímica sanguínea dos cães alimentados com dieta super prêmio nos grupos GI e GII, com valores de média e desvio-padrão

\begin{tabular}{lccc}
\hline Bioquimica sangüinea & Média \pm Desvio-padrão & Média \pm Desvio-padrão & Valores de referência \\
\hline Albumina (g/dL) & $2,30^{\mathrm{A}} \pm 0,37$ & $2,23^{\mathrm{A}} \pm 0,38$ & $2,51-3,07^{* * *}$ \\
Alfa $_{1}$ globulina (g/dL) & $0,70^{\mathrm{A}} \pm 0,13$ & $0,67^{\mathrm{B}} \pm 0,12$ & $0.58-0,80^{* * *}$ \\
Alfa $_{2}$ globulina (g/dL) & $0,64^{\mathrm{A}} \pm 0,15$ & $0,64^{\mathrm{A}} \pm 0,19$ & $0,57-0,8^{* * *}$ \\
Beta globulina (g/dL) & $1,18^{\mathrm{B}} \pm 0,26$ & $1,28^{\mathrm{A}} \pm 0,25$ & $1,41^{* * *}$ \\
Gama globulina (g/dL) & $0,65^{\mathrm{B}} \pm 0,25$ & $0,70^{\mathrm{A}} \pm 0,22$ & $0,37-0,59^{* * *}$ \\
Uréia (mg/dL) & $33,32^{\mathrm{A}} \pm 10,82$ & $32,74^{\mathrm{A}} \pm 10,03$ & $15-40^{* *}$ \\
Creatinina (mg/dL) & $0,80^{\mathrm{B}} \pm 0,31$ & $0,86^{\mathrm{A}} \pm 0,32$ & $0,5-1,5^{*}$ \\
ALT (UI/L) & $15,80^{\mathrm{B}} \pm 6,85$ & $19,11^{\mathrm{A}} \pm 8,50$ & $21-102^{*}$ \\
ALP (UI/L) & $35,75^{\mathrm{B}} \pm 17,35$ & $40,52^{\mathrm{A}} \pm 17,83$ & $20-156^{*}$ \\
\hline
\end{tabular}

AB Médias seguidas de letras diferentes, dentro da mesma linha, diferem estatisticamente pelo teste de Wilcoxon $(\mathrm{p}<0,05)$.

*KANEKO (1989)

**BUSH (1999)

***HARRUS et al.(1996)

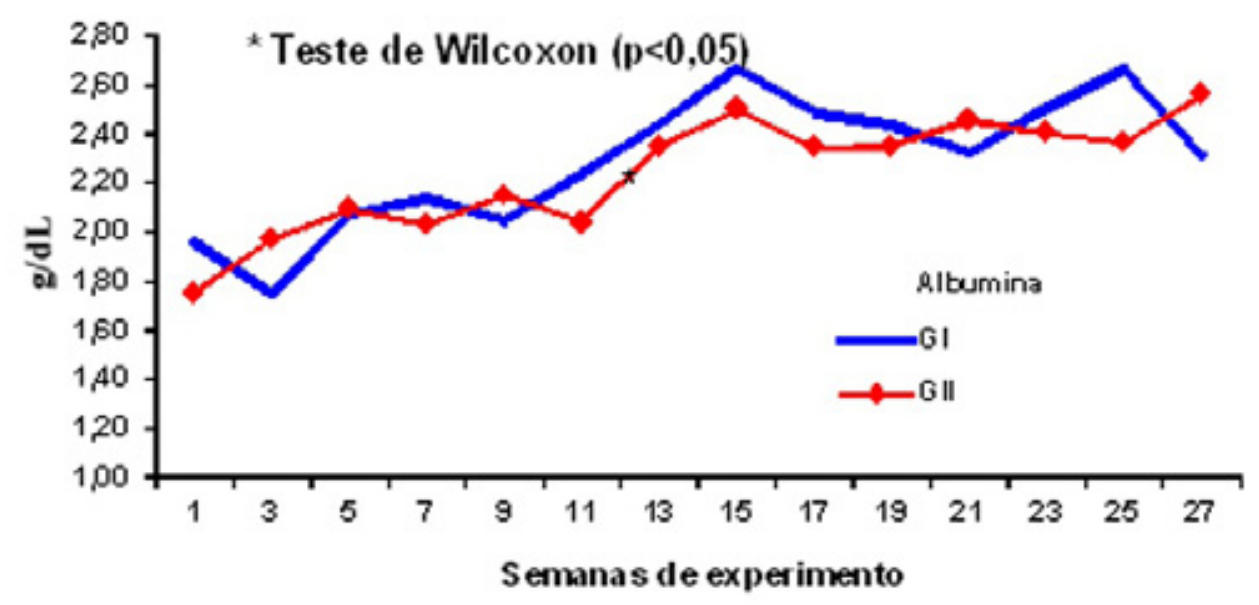

FIGURA 2 - Valores médios da albumina dos cães dos grupos GI e GII, ao longo do período de avaliação. 
A alfa1 globulina foi superior $(\mathrm{p}<0,05)$ no GI em relação ao GII. Entretanto, os valores dos dois grupos ficaram dentro dos intervalos de referência (HARRUS et al.,1996). Durante as semanas do experimento, houve diferença estatística na $17^{\mathrm{a}}$ semana (Figura 3). Os maiores valores de alfa1 globulina aliados ao maior número de linfócitos detectados no GI sugerem a estimulação de alguns componentes do processo inflamatório.

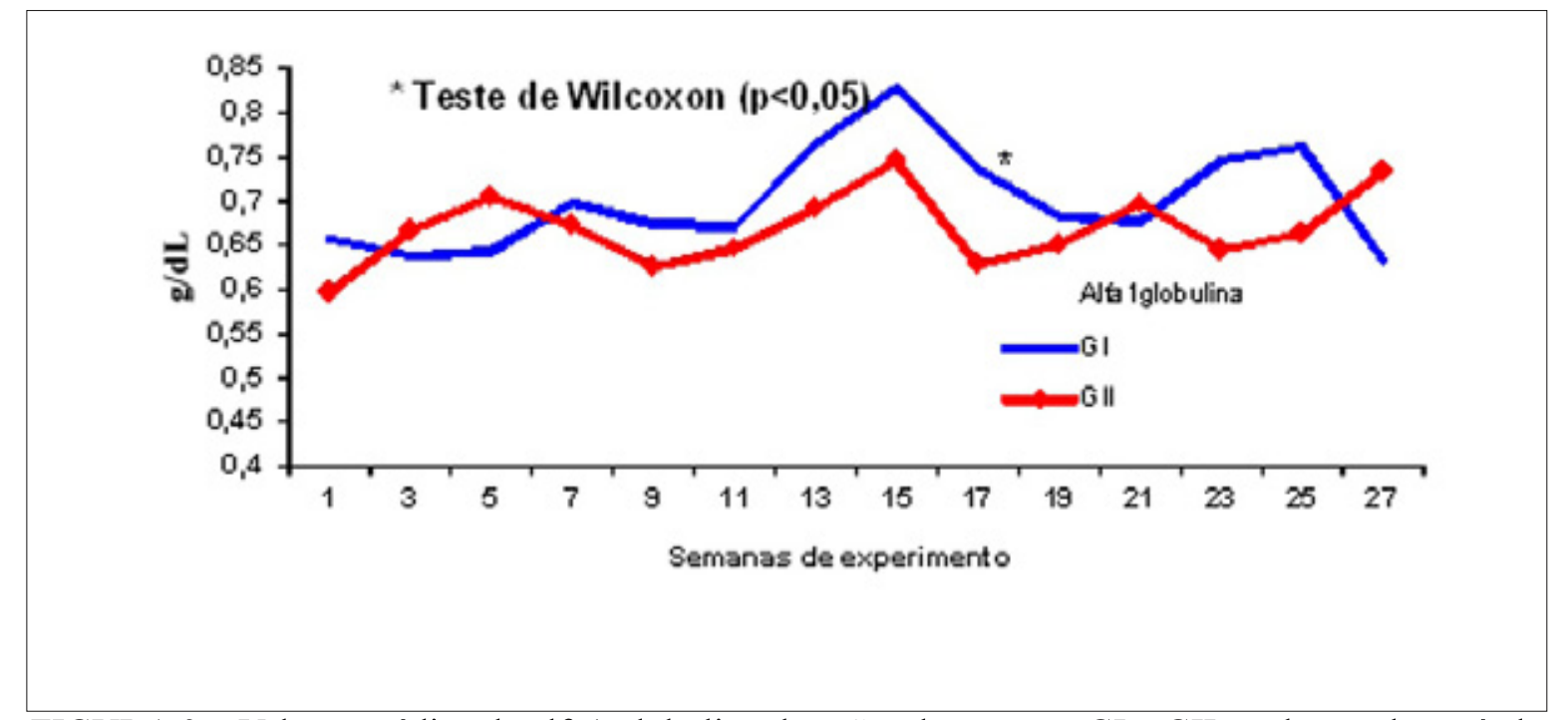

FIGURA 3 - Valores médios da alfa1 globulina dos cães dos grupos GI e GII, ao longo do período de avaliação.

Os valores médios de alfa2 globulina foram os mesmos para os cães do GI e GII e mantiveramse dentro dos intervalos de referência (HARRUS et al., 1996). Durante o período experimental não houve diferença $(p>0,05)$ entre os grupos (Figura 4$)$.

De acordo com TRAYHURN \& WOOD (2005), a obesidade em humanos induz a um estado crônico de inflamação representado pelo aumento da haptoglobina. Neste estudo não foi observada diferença $(p>0,05)$ entre os dois grupos na fração alfa2 globulina, fração que comporta a haptoglobina, sugerindo que os cães do tratamento GI, que se apresentaram com excesso de peso ou gordos, não tiveram aumento da haptoglobina.

$\mathrm{O}$ valor médio da beta globulina foi superior $(p<0,05)$ nos cães do grupo GII comparado com o GI. Os valores dos dois grupos ficaram dentro dos valores de referência (HARRUS et al., 1996). Durante as semanas do experimento, os cães do GII apresentaram valores superiores em relação aos do GI nas seguintes semanas: $9^{\mathrm{a}}(1,09$ vs. 1,27$)$ e $21^{\mathrm{a}}$ $(1,13$ vs. 1,46$)$, para os grupos GI e GII, respectivamente (Figura 5).

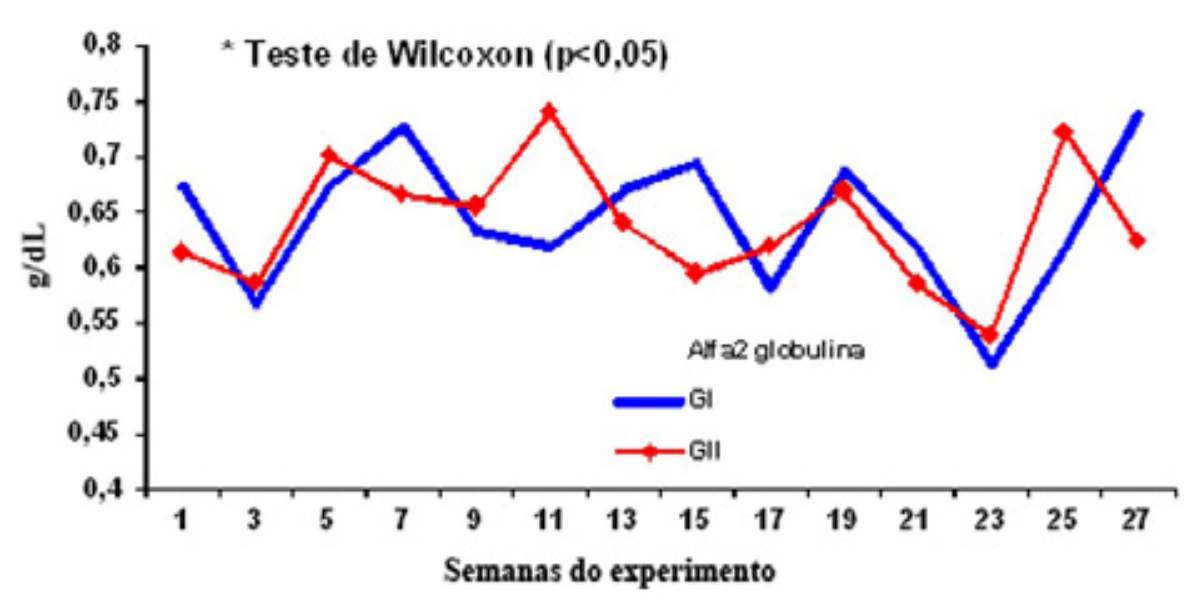

FIGURA 4 - Valores médios da alfa2 globulina dos cães dos grupos GI e GII, ao longo do período de avaliação. 


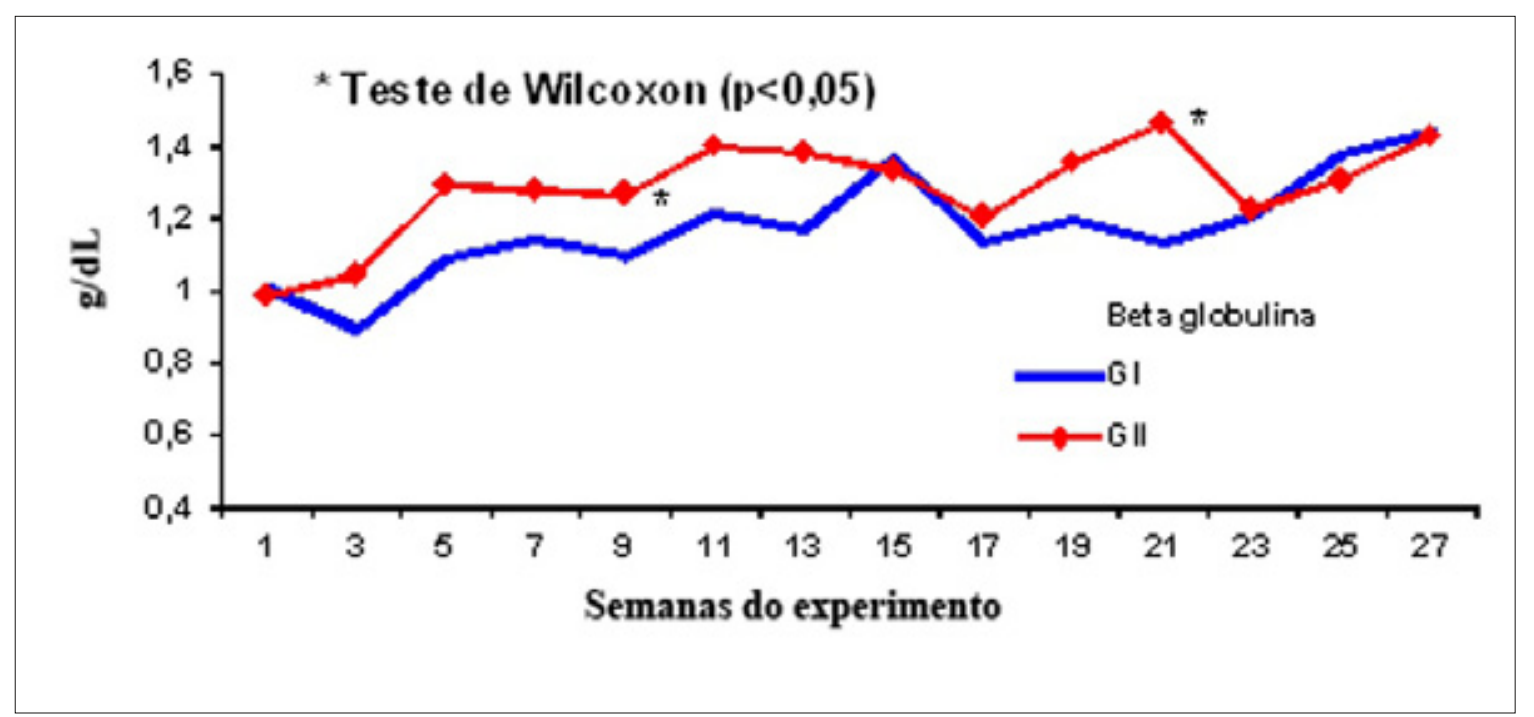

FIGURA 5 - Valores médios da beta globulina dos cães dos grupos GI e GII, ao longo do período de avaliação.

De acordo NAOUM (1999), não é raro que a zona beta globulina, por estar bem próxima à zona gama, seja encoberta pelas bandas monoclonais, podendo justificar o mesmo comportamento daquela fração quando comparado ao padrão de resposta da gama globulina.
A gama globulina apresentou média superior no grupo GII e os valores ficaram acima dos intervalos de referência. Durante as semanas do experimento houve diferença estatística na $13^{\mathrm{a}}$ semana, sendo superior no GII $(0,77 \mathrm{~g} / \mathrm{dL})$ em relação ao GI $(0,56 \mathrm{~g} / \mathrm{dL})$, conforme Figura 6.

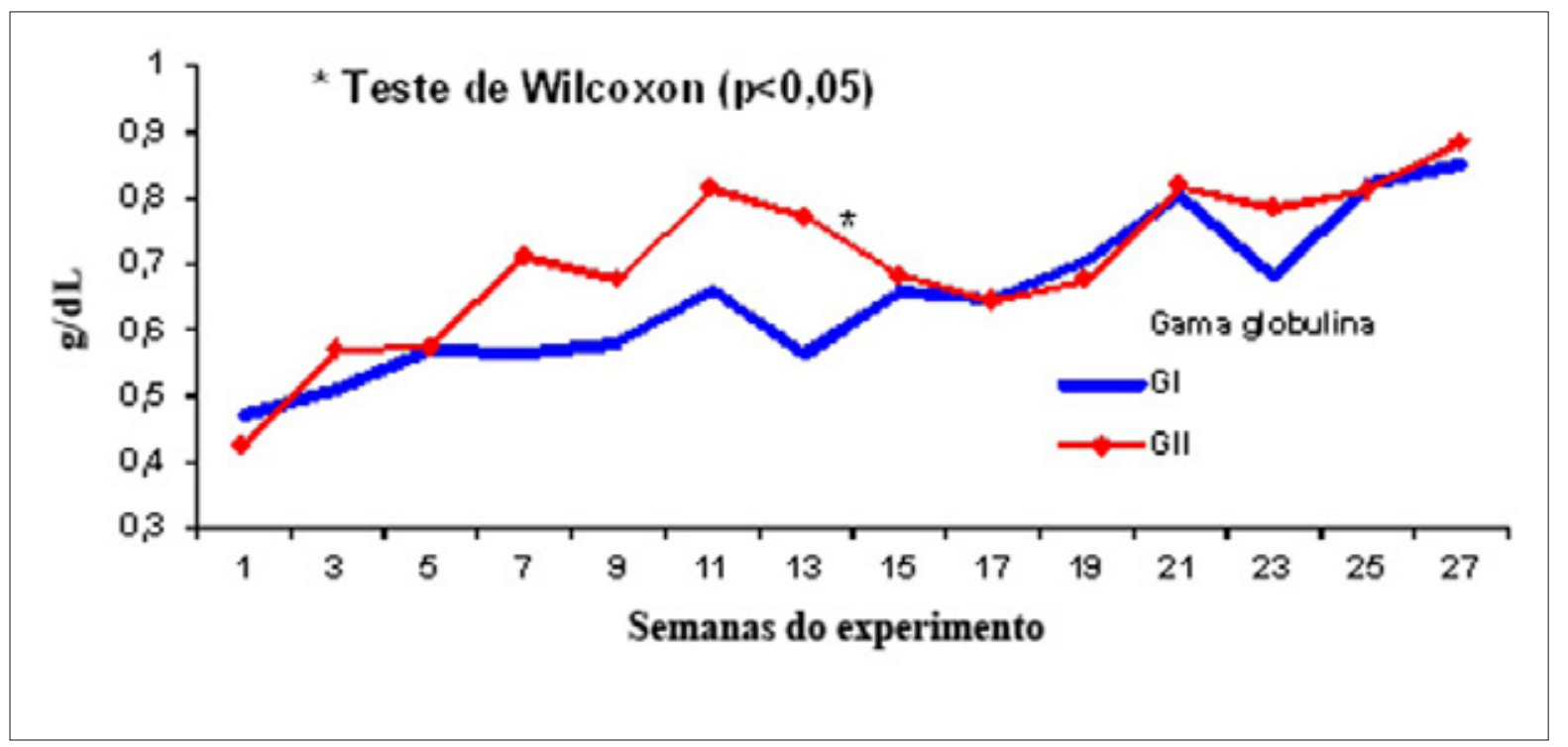

FIGURA 6 - Valores médios da gama globulina dos cães dos grupos GI e GII, ao longo do período de avaliação.

O valor médio da ALT foi superior $(\mathrm{p}<0,05)$ nos cães do GII quando comparado com o GI. As médias dos dois grupos ficaram dentro dos valores de referência. Durante o período experimental, houve diferença, sendo superior nos cães do GII em relação aos do GI em nove semanas, conforme Figura 7.

Os resultados para essa enzima foram diferen- tes em relação ao encontrado por DIEZ et. al. (2004), que não observaram diferenças na atividade sérica da ALT em cães submetidos a dietas diferentes, ou seja, uma rica em proteína e outra, em fibras.

VÄHALA et al. (1991) não observaram diferenças de valores relacionados com a idade, diferentemente deste trabalho que, com o decorrer do experimento, nos dois tratamentos, esses valores au- 
mentaram, sugerindo o efeito da idade nessa enzima. Similarmente a este trabalho, SWANSON et al. (2004) observaram o efeito da idade na atividade sérica da ALT, aumentando em cães mais velhos.

O valor médio da ALP dos cães do GII
$(40,52 \mathrm{UI})$ foi superior $(\mathrm{p}<0,05)$ em relação aos do GI $(35,75 \mathrm{UI})$; entretanto, esses valores estiveram dentro dos intervalos de referência. Durante o período experimental houve diferença $(\mathrm{p}<0,05)$, sendo superior no restrito em nove semanas (Figura 8).

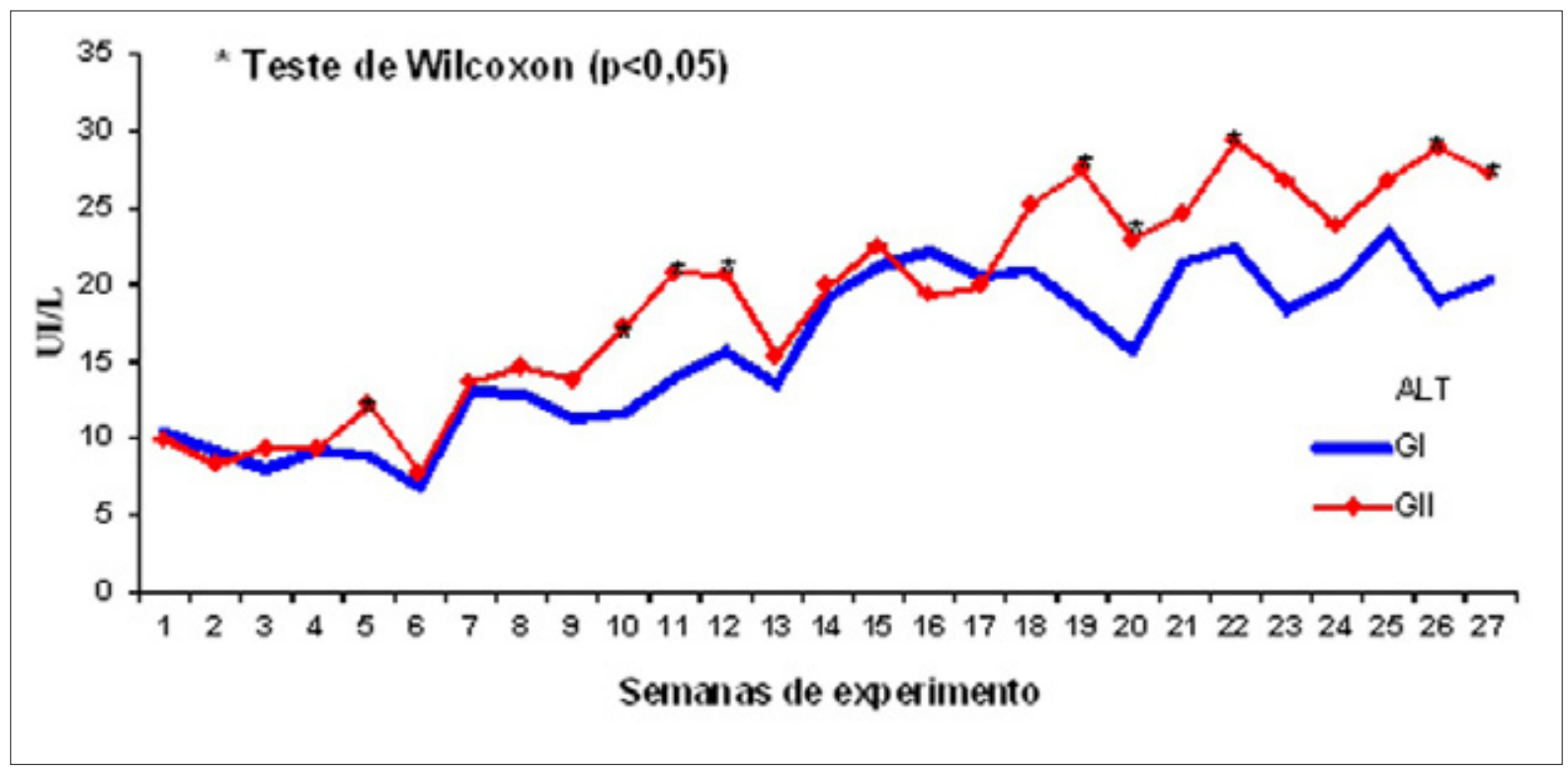

FIGURA 7 - Valores médios da ALT dos cães dos grupos GI e GII, ao longo do período de avaliação.

Na Figura 8 observa-se o declínio da atividade sérica da ALP à medida que os cães ficam mais velhos. Esse comportamento está de acordo com SWANSON et al. (2004) que, ao estudarem os efeitos da idade em cães desmamados e idosos, observa- ram que a ALP foi maior nos cães jovens. Esse fato reforça a maior atividade da fosfatase alcalina óssea no período de maior crescimento, ou seja, três a quatro meses de idade.

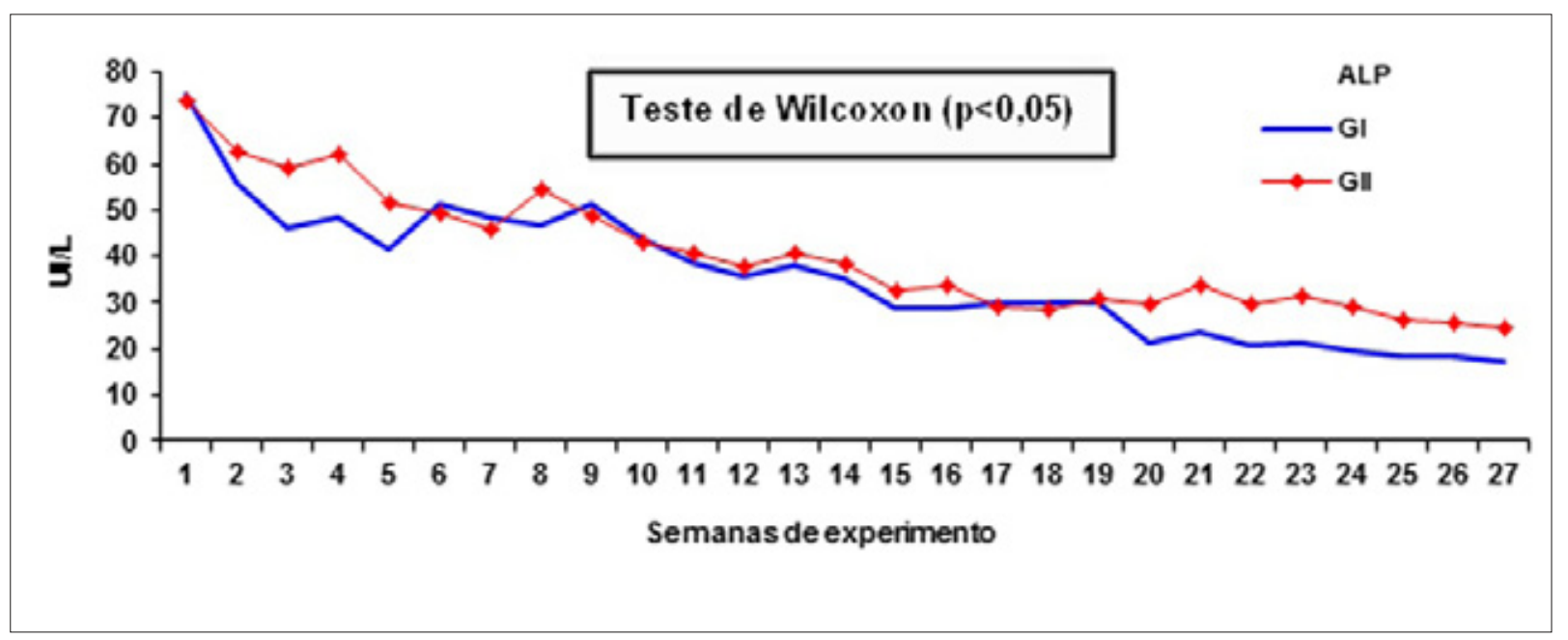

FIGURA 8 - Valores médios da ALP dos cães dos grupos GI e GII, ao longo do período de avaliação.

A determinação das concentrações séricas de uréia e creatinina é um método convencional utilizado para avaliação da função renal (NELSON \& COUTO, 2001). Mais de $90 \%$ da uréia é excretada pelos rins; entretanto, a uréia, como um indicador independente de função renal, é limitada pela variabilidade de seus níveis no sangue, como resultado de fatores não renais. De acordo com CHEW \& DI- 
BARTOLA (1992) e WHELTON et al. (1998), a uréia é o principal produto metabólico nitrogenado do catabolismo proteico do organismo, sendo sintetizada no fígado, por meio do ciclo da ornitina, utilizando amônia derivada do catabolismo de aminoácidos que, por sua vez, são provenientes da degradação de proteínas exógenas e endógenas. Assim, embora a uréia esteja mais diretamente envolvida com o metabolismo hepático, a principal utilidade clínica da determinação da uréia no soro, no estudo aqui desenvolvido, justifica-se na determinação conjunta com creatinina e na discriminação da azotemia pré e pós-renal (CHEW \& DIBARTOLA, 1992; VANDER, 1995 e WHELTON et al., 1998).

Neste trabalho, era esperado valor maior de uréia sérica nos cães do GI com ração de alta porcentagem de proteína. Contudo, não houve diferença ( $>0,05)$ para os níveis séricos médios de uréia (Tabela 1), valores dentro dos intervalos de referência (BUSH,1999). Na Figura 9 pode ser observado o comportamento da uréia sérica nas semanas de experimento entre os cães do GI e GII, evidenciando diferença $(\mathrm{p}<0,05)$ apenas na $16^{\mathrm{a}}$ semana
$(35,42 \mathrm{mg} / \mathrm{dL}$ vs. $43,28 \mathrm{mg} / \mathrm{dL})$.

A concentração sérica de creatinina ficou dentro dos intervalos de referência (KANEKO, 1989) nos dois grupos em todo o experimento, mas foi maior $(p<0,05)$, nos filhotes do GII. Houve diferença entre os grupos em quatro semanas (Figura 9).

Os animais dos dois grupos não apresentaram indícios clínicos ou laboratoriais de doença renal neste experimento.

O índice proteína-urinária:creatinina-urinária (P-u:Cr-u), de acordo com WHITE et al. (1984), substitui, com vantagens, o volume de 24 horas, já que a creatinina é produzida em taxas constantes e filtrada livremente, não sendo nem secretada nem reabsorvida pelos túbulos renais. Assim, ao aplicarse o índice, o efeito do volume de urina sobre a concentração de proteína em uma única amostra é anulado. De acordo com LULICH \& OSBORNE (1990), cães hígidos apresentam índice P-u:Cr-u menor que 0,5 , sendo valores entre 0,5 e 1,0 , questionáveis e valores maiores que 1,0 anormais.

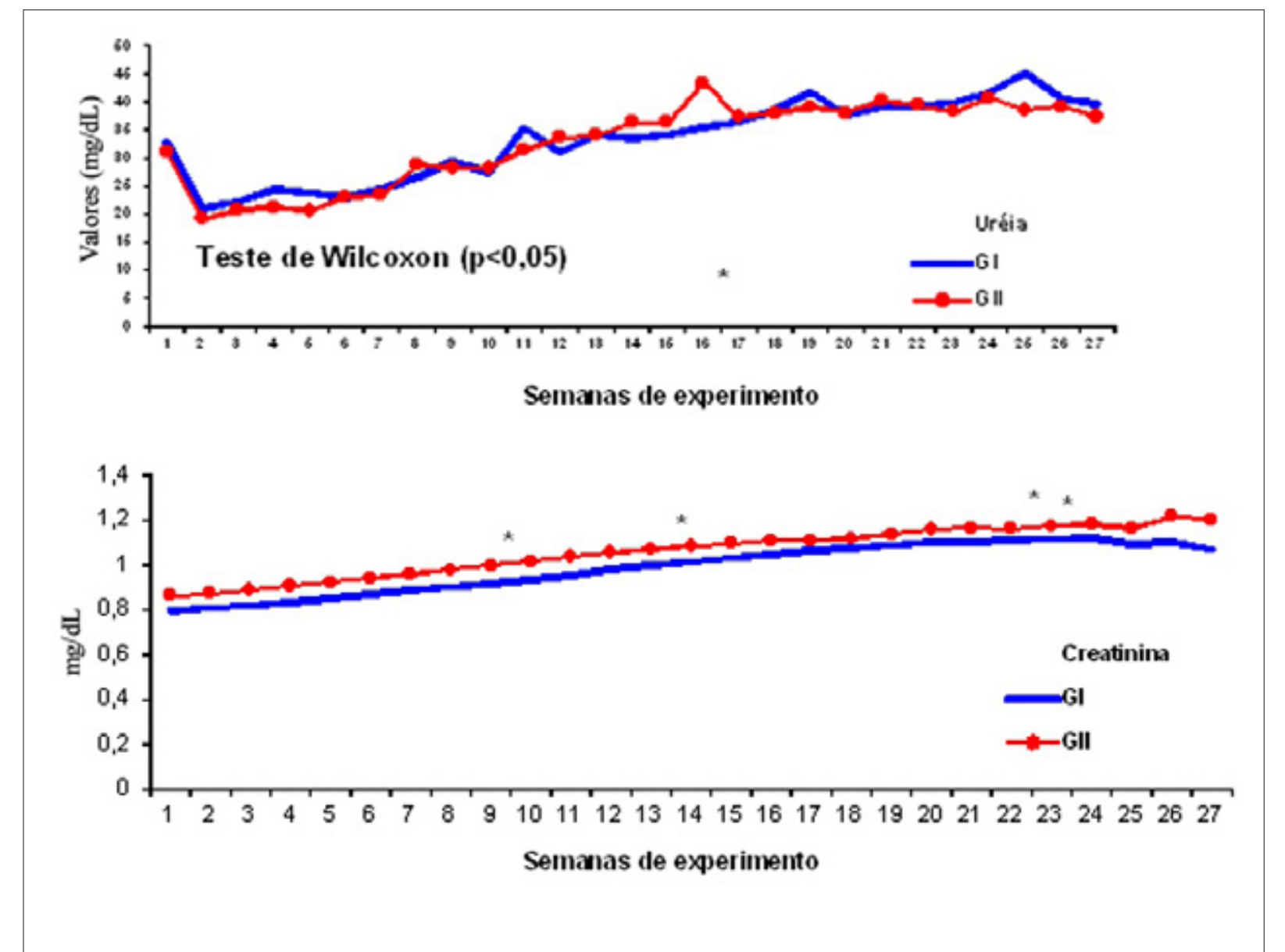

FIGURA 9 - Comportamento da uréia e creatinina séricas, dos cães dos grupos GI e GII, ao longo do período de avaliação. 
$\mathrm{O}$ índice $\mathrm{P}-\mathrm{u}: \mathrm{Cr}-\mathrm{u}$ apresentou valores de média e desvio padrão de $0,27(0,23)$ e $0,24(0,13)$ para os grupos GI e GII, respectivamente, sem diferença $(p>0,05)$ entre eles. Houve diferença $(\mathrm{p}<0,05)$ apenas na primeira semana de experimento, sendo superior nos filhotes do GII (Figura 10). Em dois momentos deste trabalho, na segunda e na $11^{\text {a }}$ semanas, os cães do GI apresentaram valores médios de índice $\mathrm{P}-\mathrm{u}: \mathrm{Cr}-\mathrm{u}$ maiores que 0,5 o que pode ser atribuído à ingestão excessiva de proteína pelos animais desse grupo.

TOLEDO (2001) encontrou valores entre 0,22 e 0,13 , respectivamente, para machos e fêmeas, sendo os valores encontrados nos machos próximos aos achados do estudo em questão. Valores superiores aos aqui observados foram descritos por ZARAGOZA et al. (2003), que encontraram médias de 0,5 no cálculo desse índice em cães sadios de raças e sexo variados estando, portanto, no limite da normalidade.

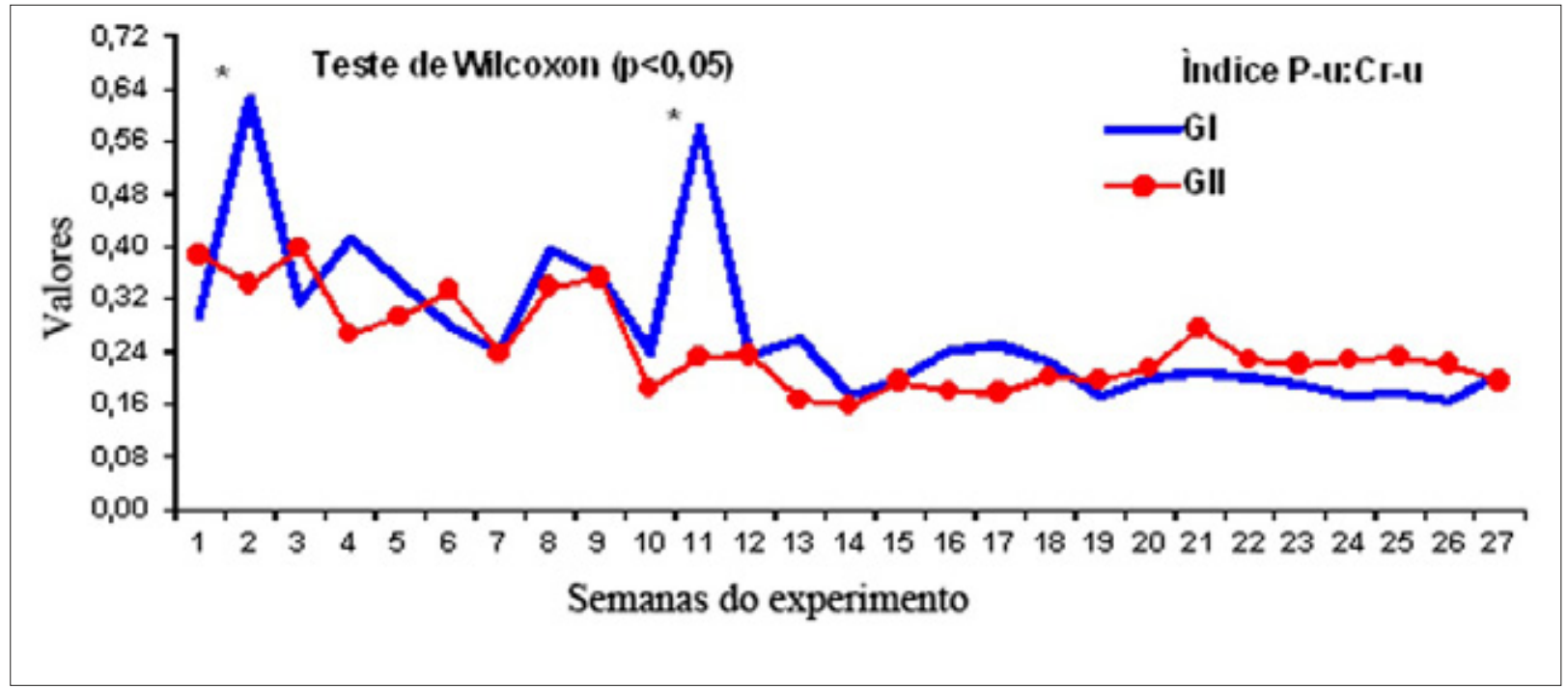

FIGURA 10 - Valores médios da relação proteína e creatinina urinária dos cães dos grupos GI e GII, ao longo do período de avaliação.

\section{CONCLUSÕES}

A alimentação oferecida à vontade com ração de alta digestibilidade, $34 \%$ de $\mathrm{PB}$ e $16 \%$ de lipídeos, não está relacionada a alterações hematológicas e de função hepática e renal em filhotes de cães da raça Dogue Alemão.

\section{FONTE DE FINANCIAMENTO - Nutron Alimentos}

\section{REFERÊNCIAS}

AGAR, S. Small animal nutrition. Edinburgh: Butterworth-Heinemann, 2001. $187 \mathrm{p}$.

ARMSTRONG, P. J.; LUND, E. M. Changes in body composition and energy balance with aging. Veterinary Clinical Nutrition, Montreal, 1996. v.3, .n.3, p.83-87.

BURKHOLDER, W. J.; TOLL, P. W. Controle da Obesidade. In: HAND, M.S., THATCHER, C.D.; REMILLARD, R. L.; ROUDEBUSH, P. Small animal clinical nutrition. 4 ed. Topeka: Mark Morris Institute, 2000. p.401-430.
BUSH, B. M. Interpretación de los análisis de laboratorio para clínicos de pequeños animales. Harcourt. Espanha. 1999. 616p.

CHEW, D. J.; DIBARTOLA, S. P. Diagnóstico e fisiopatologia da moléstia renal. In: ETTINGER, S. J. (Ed.). Tratado de medicina interna veterinária: moléstias do cão e do gato. 3.ed. São Paulo: Manole, 1992. v.4, p.1975-2046.

DIEZ, M.; MICHAUX, C.; JEUSETTE, I.; BALDWIN, P., ISTASSE, L.; BIOURGE, V. Evolution of blood parameters during weight loss in experimental obese Beagle dogs. Journal of Animal Physiology and Animal Nutrition, Berlin, v.88, p.166-171, 2004.

ECKERSALL, P. D. Recent advances and future prospects for the use of acute phase proteins as markers of disease in animals. Revue de Médiccine Vétérinaire, Toulouse, v.151, p.577-584, 2000.

EDNEY, A. T. B.; SMITH, P.M. Study of obesity in dogs visiting veterinary practices in the United Kingdom. The Veterinary Record, London, v.118, n.14, p.391-396, 1986.

FERREIRA, R. P. Função renal de cães adultos sadios 
alimentados com diferentes teores de proteína bruta. 2006. 81f. Dissertação (Mestrado em Ciência Animal) Escola de Veterinária da Universidade Federal de Goiás. disponível em http://www.ufg.br/this2/uploads/files/66/Dissertacao2006_Renata_Pereira.pdf

FINCO, D. R. Urinary protein loss. In: OSBORNE, C. A.; FINCO, D. R. (Ed.) Canine and feline nephrology and urology. Philadelphia: Williams \& Wilkins, 1995. p.211-215.

HAND, M. S.; ARMSTRONG, J.; ALLEN, T. A. Obesity: Occurrence, treatment, and prevention. The Veterinary Clinics of North America: Small Animal Practice, Philadelphia, v.19, n.3, p.447-474, 1989.

HARRUS, S., WANER, T., AVIDAR, Y., BOGIN, E., PEH, H., BARK, H. Serum protein alterations in canine ehrlichiosis. Veterinary Parasitology, v.66, p.241-249. 1996.

JERICÓ, M. M.; SCHEFFER, K. C. Aspectos epidemiológicos dos cães obesos na cidade de São Paulo. Clínica Veterinária, São Paulo, v.7, n.37, p.25-29, 2002.

JERICÓ, M. M.; SILVA, M. B. F. P.; MACHADO, F. L. A. Avaliação cardiovascular em cães obesos: mensuração da pressão arterial e achados eletrocardiográficos. Clinica Veterinária, São Paulo, v.11, n.61, p.66-72, 2006.

KANECO, J. J. Clinical biochemistry of domestic animals. San Diego: Academic Press, 1989. 932p

LEWIS, D. L.; MORRIS, L. M.; HAND, S. M. Small animal clinical nutrition III. Topeka: Mark Morris Institute, 1994.369 p.

LIPPERT, A. C. The metabolic response to injury: enteral and parenteral nutritional support. In: MURTAUGH, R.; KAPLAN, P. M. (Ed.). Veterinary emergency and critical care. Saint Louis: Mosby-Year Book, 1992. p.593617.

LULICH, J. P.; OSBORNE, C. A. Interpretation of urine protein-creatinine ratios in dogs with glomerular and nonglomerular disorders. The Compendium on Continuing Education for the Practicing Veterinarian, Princeton. v. 12, n. 1 p. $59-72,1990$.

NAOUM, P. C. Eletroforeses - técnicas e diagnósticos. 2.ed. São Paulo: Santos, 1999. 154 p.

NAP, R. C.; HAZEWINKEL, H. A. W.; VOORHOUT, G.; BROM, W. E.; GOEDEGEBUURE, S. A.; KLOOSTER, A. T. V. Growth and skeletal development in Great Dane puppies fed different levels of protein intake. Journal of Nutrition, Philadelphia, v.121, n.11, p.107-113,
1991.

NELSON, R. W., COUTO, C. G. Medicina interna de pequenos animais. Guanabara Koogan, Rio de Janeiro, RJ. 2.ed., 2001. 1084 p.

SAMPAIO, I. B. M. Estatística aplicada à experimentação animal. Belo Horizonte: FEPMV,1998. 221p.

SWANSON, K. S.; KUZMUK, K. N.; SCHOOK, L. B.; FAHEY JR. G. C. Diet affects nutrient digestibility, hematology, and serum chemistry of senior and wealing dogs. Journal of Animal Science, Champaign, v.82, p.1713-1724, 2004.

TOLEDO, E. G. H. Perfil eletroforético de proteínas séricas e urinárias de cães normais e de portadores de insuficiência renal crônica. 2001. 52f. Dissertação (Mestrado em Medicina Veterinária) - Faculdade de Ciências Agrárias e Veterinárias, Universidade Estadual Paulista, Jaboticabal.

TRAYHURN, P., WOOD, L. S. Signalling role of adipose tissue: adipokines and inflammation in obesity. Biochemical Society Transactions, v.33, part 5, p. 1078-1081, 2005

UFV, UNIVERSIDADE FEDERAL DE VIÇOSA. Sistema de análises estatísticas e genéticas: Manual do usuário (SAEG). Versão 8.1, Viçosa, 2003. 301 p.

VÄHALA, J., POSPISIL, J., POKORNY, R., KASE, F. Blood serum biochemical values of cape hunting dogs (Lycaon pictus): variations whit age and sex. Acta Veterinaria, Scandinavica, v.60, p.219-224,1991.

VANDER, A. J. Renal physiology. 5.ed. New York: McGraw-Hill, 1995. 238p.

WHELTON, A.; WATSON, A. J.; ROCK, R. C. Metabólitos nitrogenados e função renal. In: BURTIS, C. A.; ASHWOOD, E. R. (Ed.). Fundamentos de química clínica. 4.ed. Rio de Janeiro: Guanabara Koogan, 1998. p.552-574.

WHITE, V. OLIVIER, N.B., REIMANN, K., JOHNSON, C. Use of protein-to-creatinine in a single urine specimen for quantification of canine proteinuria. Journal of the American Veterinary Medical Association, v.185, n.8, p.882-885, 1984.

ZARAGOZA, C.; BARRERA, R.; CENTENO, F.; TAPIA, J. A.; MAÑÉ, M. C. Characterization of renal damage in canine leptospirosis by sodium dodecyl sulphate polyacrylamide gel electrophoresis (SDS - PAGE) and western blotting of the urinary proteins. Journal of Comparative Pathology, Edinburgh, v.129, p.169-178, 2003. 